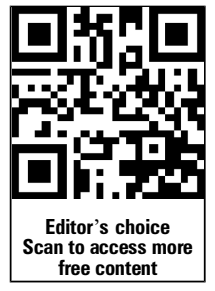

${ }^{1}$ Cardiology Unit, Department of Medicine, Karolinska Institute, Stockholm, Sweden ${ }^{2}$ School of Medicine, Muhimbili University of Health and Allied Sciences, Dar es Salaam, Tanzania

${ }^{3}$ Department of Cardiology, Karolinska University Hospital, Stockholm, Sweden ${ }^{4}$ Cardiovascular Center, Muhimbili National Hospital, Dar es Salaam, Tanzania ${ }^{5}$ Nuffield Department of Clinical Medicine, University of Oxford, Oxford, UK

Correspondence to Dr Abel Makubi, Cardiology Unit, Department of Medicine, Karolinska Institute, Stockholm, Sweden; makubi55@gmail.com

Received 31 January 2014 Revised 11 March 2014 Accepted 26 March 2014 Published Online First 17 April 2014

\title{
Contemporary aetiology, clinical characteristics and prognosis of adults with heart failure observed in a tertiary hospital in Tanzania: the prospective Tanzania Heart Failure (TaHeF) study
}

\author{
Abel Makubi, ${ }^{1,2}$ Camilla Hage, ${ }^{1,3}$ Johnson Lwakatare, ${ }^{2,4}$ Peter Kisenge, ${ }^{4}$ \\ Julie Makani, ${ }^{2,5}$ Lars Rydén, $^{1}$ Lars $\mathrm{H}$ Lund $^{1,3}$
}

ABSTRACT

Objective This study aimed to describe the contemporary aetiology, clinical characteristics and mortality and its predictors in heart failure (HF) in Tanzania.

Methods Design; Prospective observational study. Setting; Cardiovascular Center of the Muhimbili National Hospital in Dar es Salaam, Tanzania. Patients $\geq 18$ years of age with HF defined by the Framingham criteria.

Main outcome measure All-cause mortality. Results Among 427 included patients, 217 (51\%) were females and the mean (SD) age was 55 (17) years. HF aetiologies included hypertension (45\%), cardiomyopathy (28\%), rheumatic heart disease (RHD) $(12 \%)$ and ischaemic heart disease $(9 \%)$. Concurrent atrial fibrillation (AF), clinically significant anaemia, diabetes, tuberculosis and HIV were found in 16\%, $12 \%, 12 \%, 3 \%$ and $2 \%$, respectively, while warfarin was used in $3 \%$ of the patients. The mortality rate, 22.4 per 100 person-years over a median follow-up of 7 months, was independently associated with $A F, H R$ 3.4 ( $95 \%$ Cl 1.6 to 7.0$)$; in-patient 3.2 (1.5 to 6.8 ); anaemia 2.3 (1.2 to 4.5); pulmonary hypertension 2.1 (1.1 to 4.2$)$ creatinine clearance 0.98 (0.97 to 1.00) and lack of education 2.3 (1.3 to 4.2).

Conclusions In HF in Tanzania, patients are younger than in the developed world, but aetiologies are becoming more similar, with hypertension becoming more and RHD less important. Predictors of mortality possible to intervene against are anaemia, AF and lack of education.

\section{INTRODUCTION}

In developed countries, the prevalence and incidence of heart failure (HF) are $2-3 \%$ and $0.5 \%$, respectively, and increasing with age. ${ }^{1}$ The aetiology, clinical characteristics, therapy and prognosis of this syndrome have been extensively studied in developed but considerably less in developing countries, and $\mathrm{HF}$ is largely unexplored in Sub-Saharan Africa (SSA). Still, the diagnosis accounts for over $30 \%$ of hospital admissions in cardiovascular and $3-7 \%$ in internal medicine units in this region. ${ }^{2}$

Historically, the main aetiologies of HF in SSA have been rheumatic heart disease and cardiomyopathies, ${ }^{3}$ whereas hypertension and ischaemic heart disease are more important in the developed world. $^{4-6}$ Aetiologies in SSA may be changing towards developed world patterns ${ }^{7-10}$ but may also vary according to setting and geographical region. Comorbidities, predictors of prognosis and the beneficial effects and widespread use of neurohormonal antagonist drugs have been well described in the developed world, but such data are limited in SSA, and there are concerns that mortality remains high. 78

Therefore, the objective was to assess the contemporary aetiology, clinical characteristics, prognosis and predictors of prognosis of $\mathrm{HF}$ in Tanzania.

\section{METHODS}

Study setting, design and participants

The Tanzania Heart Failure (TaHeF) study was a prospective observational study conducted at the Cardiovascular Centre of the Muhimbili National Hospital (MNH) (figure 1). This centre is a national referral hospital serving about 45 million Tanzanian people. The study was conducted from February 2012 to August 2013. The inclusion criterion was clinical diagnosis of $\mathrm{HF}$ according to the Framingham criteria. ${ }^{11}$ Exclusion criteria were age $<18$ years and declining to participate.

\section{Data collection}

Patients were screened $(\mathrm{n}=521)$ and included $(n=427)$ in the outpatient clinic and cardiac wards (figure 1). With very few exceptions, the patients were investigated after having been stabilised into a compensated state. Fifty demographic, social, clinical, comorbidity, laboratory (MNH Central Pathology Laboratory), ECG and echocardiographic (General electric Vivid 5 with a $2.5-5 \mathrm{MHz}$ probe) variables (table 1 ) were obtained. LVEF was determined by consensus of two senior cardiologists (JL and $\mathrm{PK}$ ) at $\mathrm{MNH}$.

\section{Outcome measure}

This was all-cause mortality. Patients were followed in the outpatient clinic on a monthly basis. Those who missed their appointments were contacted through mobile phones. Follow-up in clinic and phone contact was sought until August 2013. Patients who could not be reached were censored alive at the last confirmed contact or considered lost to follow-up if no contact was made after 


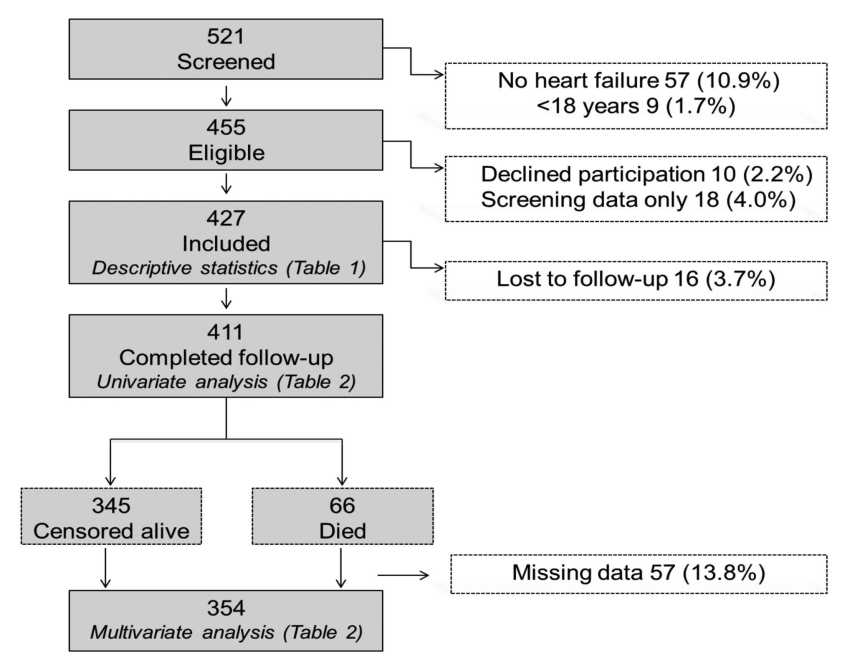

Figure 1 Flow chart of patients recruited into the Tanzania Heart Failure study.

enrolment. In patients who died outside of $\mathrm{MNH}$, date of death was obtained from next of kin (figure 1).

\section{Definitions and diagnostic criteria}

The underlying probable cause of HF was clinically determined by consensus of a senior medical specialist (AM) and senior cardiologists (JL and PK) through a combination of case history, hospital records, physical examination, chest X-rays, ECG and echocardiographic recordings. Criteria for hypertensive HF, rheumatic heart disease and cardiomyopathy were modified after the chronic HF cohort in the Heart of Soweto Study, ${ }^{10}$ according to the following definitions: hypertensive-HF combined with a documented history of hypertension and echocardiographic findings of increased LV septal thickness $(>1.3 \mathrm{~cm})$, diastolic dysfunction and/or LV systolic dysfunction; ischaemic- $-\mathrm{HF}$ combined with ECG and/or echocardiographic findings indicating ischaemic heart disease (myocardial injury; abnormal regional wall motion) or coronary artery disease verified by angiography; rheumatic-HF with a documented history of rheumatic heart disease supported with echocardiographic moderate-to-severe valvular dysfunction; idiopathic dilated cardiomyopathy-HF of indeterminate origin with LV systolic dysfunction and LVEDD $\geq 55 \mathrm{~mm}$; peripartum cardiomyopathy- HF due to left ventricular systolic dysfunction by the end of pregnancy or the months following delivery following exclusion of other causes $^{12}$; other-HF due to congenital heart disease, hypertrophic cardiomyopathy, restrictive cardiomyopathy, endomyocardial fibrosis and secondary to HIV infection, tuberculosis and chronic lung disease.

Clinically significant anaemia was defined as haemoglobin $<10 \mathrm{~g} / \mathrm{dL}$ for both sexes as previously defined in other SSA settings. ${ }^{7}$ Pulmonary hypertension was defined as estimated right ventricular systolic pressure $>35 \mathrm{~mm} \mathrm{Hg}$ on echocardiography, ${ }^{10}$ and graded as mild $(36-50 \mathrm{~mm} \mathrm{Hg})$, moderate $(51-60 \mathrm{~mm} \mathrm{Hg})$ and severe (>60 $\mathrm{mm} \mathrm{Hg}$ ).

Creatinine clearance was calculated according to the CockcroftGault formula. Formal education was defined as primary school education or above and unemployment as not on private or governmental official duties with financial monthly income.

\section{Statistical analysis}

Continuous variables were tested for normality distribution using normal probability plots and reported as mean \pm SD or median (IQR) as appropriate. The influence of selected characteristics on survival was assessed by Kaplan-Meier plots. Univariate and multivariate Cox regression analyses were used to identify predictors of mortality. Selected continuous variables were categorised according to previously established clinically relevant criteria ${ }^{7}$ (table 2). Criteria for entry into the multivariate model were clinical relevance (age and gender) or $\mathrm{p}$ value $\leq 0.10$ in univariate analysis. Patients who were lost to follow-up (16 of 427) were excluded from survival analyses and patients who had missing data (57 of 411 patients on follow-up) were excluded from multivariate analysis, leaving 354 patients included in the multivariate analysis (figure 1). All analyses were performed using SPSS V.17, and a two-sided $\mathrm{p}$ value of 0.05 was considered statistically significant.

\section{RESULTS}

\section{Baseline characteristics}

The median follow-up was 7 (4-14) months. Most patients $(73 \%)$ were recruited from the outpatient clinic. Two hundred and twenty $(51 \%)$ were females and age $( \pm$ SD) was 55 \pm 17 years. Figure 1 shows the flow of patients recruited into the TaHeF study. The proportion of the patients fulfilling the major Framingham criteria were cardiomegaly 86\%, paroxysmal nocturnal dyspnoea $63 \%$, third heart sound 62\%, orthopnea $60 \%$, pulmonary oedema $29 \%$, raised jugular venous pressure $27 \%$ and pulmonary rales $21 \%$. The corresponding proportions for the minor criteria were exercise-induced dyspnoea $85 \%$, peripheral oedema $62 \%$, tachycardia 45\%, nocturnal cough $34 \%$, hepatomegaly $29 \%$ and pleural effusion $21 \%$.

\section{Aetiology, clinical characteristics and therapy}

The aetiology of HF was hypertension in $45 \%$ of the patients while cardiomyopathies were behind $28 \%$, rheumatic heart disease $12 \%$, ischaemic heart disease $9 \%$ and other reasons (probable tuberculosis or HIV-related cardiomyopathies, endomyocardial fibrosis and obstructive lung disease) in 6\%. The distribution of the various aetiologies by patient age is shown in figure 2. Among those with cardiomyopathies, HF due to idiopathic dilated cardiomyopathy was most frequent (81\%), followed by postpartum cardiomyopathy (15\%) while hypertrophic and restrictive cardiomyopathies were rare (5\%). Rheumatic mitral disease with regurgitation was the most prevalent valvular lesion $(81 \%)$, followed by mitral stenosis $(15 \%)$ and aortic regurgitation (3\%).

Table 1 lists patient characteristics overall and for those who had died or survived at the last follow-up. Atrial fibrillation was present in $16 \%$ of the patients and clinically significant anaemia in $12 \%$. Mean LVEF was $41 \pm 12 \%$, and $62 \%$ of the patients had a LVEF $<45 \%$. When present, pulmonary hypertension was usually mild (83\%). Patients with ischaemic heart disease and those with cardiomyopathies had a lower mean LVEF (38\%) than those with hypertensive (41\%) and rheumatic heart disease (44\%). Only $9 \%$ had creatinine clearance $<30 \mathrm{~mL} / \mathrm{min}$.

Angiotensin-converting enzyme inhibitors (ACEI) and/or angiotensin receptor blockers (ARBs) were used in 92\%, loop diuretics in $88 \%$ and $\beta$-blockers in $42 \%$, whereas warfarin was used in $3 \%$.

\section{Survival}

During follow-up, 66 patients died, resulting in a mortality rate of 22.4 per 100 person-years of observation. The overall 6-month survival rate was $90 \%$ (figure $3 \mathrm{~A}$ ). The 6-month survival rates for patients with and without anaemia and atrial fibrillation were $60 \%$ vs $94 \%$ and $63 \%$ vs $96 \%$ (both $\mathrm{p}<0.001$ ), 
Table 1 Baseline characteristics of the patient population overall and by survival status

\begin{tabular}{|c|c|c|c|c|c|c|c|}
\hline \multirow[b]{3}{*}{ Variable } & \multicolumn{3}{|c|}{ All patients $(n=427)$} & \multicolumn{4}{|c|}{ Survival status } \\
\hline & \multirow[b]{2}{*}{ Missing (n) } & \multirow[b]{2}{*}{$\mathbf{n}$} & \multirow[b]{2}{*}{$(\%)$} & \multicolumn{2}{|c|}{ Survivors $(n=345)$} & \multicolumn{2}{|c|}{ Died $(n=66)$} \\
\hline & & & & $\mathrm{n}$ & $(\%)$ & $\mathrm{n}$ & $(\%)$ \\
\hline Follow-up (months; median IQR) & 16 & 7 & $4-14$ & 8 & $5-15$ & 5 & $3-10$ \\
\hline \multicolumn{8}{|l|}{ Social demographics } \\
\hline Age (years; mean, SD) & 0 & 55 & 17 & 53 & 17 & 62 & 17 \\
\hline Males & & 210 & 49 & 170 & 49 & 34 & 51 \\
\hline From Dar es Salaam & 0 & 273 & 64 & 225 & 65 & 38 & 57 \\
\hline Formal education & 0 & 337 & 80 & 281 & 81 & 46 & 70 \\
\hline Unemployed & 0 & 211 & 49 & 157 & 48 & 37 & 56 \\
\hline \multicolumn{8}{|l|}{ Clinical } \\
\hline Location of recruitment & 0 & & & & & & \\
\hline Inpatient & & 117 & 27 & 63 & 18 & 48 & 73 \\
\hline Outpatient & & 310 & 73 & 282 & 82 & 18 & 37 \\
\hline HF duration (months; median, IQR) & 0 & 13 & $4-28$ & 13 & $4-30$ & 13 & $5-31$ \\
\hline$<6$ months & & 140 & 33 & 117 & 34 & 19 & 29 \\
\hline$\geq 6$ months & & 287 & 67 & 228 & 66 & 47 & 71 \\
\hline NYHA class & 0 & & & & & & \\
\hline ॥ & & 85 & 19 & 78 & 22 & 5 & 8 \\
\hline III & & 208 & 48 & 175 & 51 & 26 & 39 \\
\hline IV & & 134 & 31 & 92 & 27 & 35 & 53 \\
\hline Previous CV admission & 0 & 224 & 52 & 169 & 49 & 47 & 71 \\
\hline \multicolumn{8}{|l|}{ Comorbidities } \\
\hline Diabetes & 0 & 50 & 12 & 37 & 11 & 12 & 18 \\
\hline Atrial fibrillation & 0 & 67 & 16 & 25 & 7 & 42 & 64 \\
\hline Stroke & 0 & 16 & 4 & 12 & 4 & 4 & 6 \\
\hline Tuberculosis & 0 & 11 & 3 & 9 & 3 & 2 & 3 \\
\hline Asthma/COPD & 0 & 13 & 3 & 10 & 3 & 3 & 5 \\
\hline HIV & 0 & 10 & 2 & 8 & 2 & 2 & 3 \\
\hline Thyroid disease & 0 & 3 & 1 & 3 & 1 & 0 & 0 \\
\hline Deep venous thrombosis & 0 & 4 & 1 & 3 & 1 & 1 & 2 \\
\hline Pulmonary hypertension & 39 & 73 & 17 & 34 & 10 & 39 & 59 \\
\hline \multicolumn{8}{|l|}{ Pharmacological treatment } \\
\hline ACEI/ARB & 0 & 393 & 92 & 317 & 92 & 61 & 9 \\
\hline$\beta$-Blockers & 0 & 177 & 42 & 142 & 41 & 27 & 41 \\
\hline Calcium channel blockers & 0 & 79 & 19 & 63 & 18 & 15 & 23 \\
\hline Loop diuretics & 0 & 374 & 88 & 280 & 82 & 60 & 91 \\
\hline Aldosterone antagonist & 0 & 308 & 72 & 246 & 71 & 51 & 77 \\
\hline Digoxin & 0 & 165 & 39 & 125 & 36 & 34 & 52 \\
\hline Nitrates & 0 & 274 & 64 & 221 & 64 & 40 & 61 \\
\hline Hydralazine & 0 & 19 & 4 & 17 & 5 & 1 & 2 \\
\hline Statins & 0 & 33 & 8 & 27 & 8 & 6 & 9 \\
\hline Aspirin & 0 & 109 & 26 & 91 & 26 & 1 & 24 \\
\hline Clopidogrel & 0 & 21 & 5 & 19 & 6 & 2 & 3 \\
\hline HAART & 0 & 10 & 2 & 8 & 2 & 3 & 5 \\
\hline Warfarin & 0 & 11 & 3 & 10 & 3 & 1 & 2 \\
\hline Physical examination & & Mean & SD & Mean & SD & Mean & SD \\
\hline Body mass index $\left(\mathrm{kg} / \mathrm{m}^{2}\right)$ & 0 & 25.5 & 5 & 26 & 5 & 24 & 5 \\
\hline Radial pulse (beats/min) & 0 & 89 & 18 & 89 & 18 & 88 & 20 \\
\hline Blood pressure $(\mathrm{mm} \mathrm{Hg})$ & 0 & & & & & & \\
\hline Systolic & & 132 & 28 & 133 & 27 & 126 & 31 \\
\hline Diastolic & & 84 & 16 & 86 & 15 & 79 & 17 \\
\hline \multicolumn{8}{|l|}{ Laboratory/echocardiography } \\
\hline Haemoglobin (g/dl) & 26 & 12 & 2 & 12 & 2 & 10 & 2 \\
\hline Anaemia (<10 g/dL), n (\%) & & 48 & 12 & 20 & 6 & 6 & 39 \\
\hline Creatinine clearance $(\mathrm{ml} / \mathrm{min})$ & 21 & 69 & 31 & 73 & 30 & 55 & 29 \\
\hline Serum cholesterol mmol/L) & 31 & 5.0 & 1 & 5 & 1 & 4 & 1 \\
\hline Serum $\mathrm{Na}^{+}(\mathrm{mmol} / \mathrm{L})$ & 22 & 140 & 13 & 141 & 7 & 142 & 24 \\
\hline Serum $\mathrm{K}^{+}(\mathrm{mmol} / \mathrm{L})$ & 22 & 4 & 1 & 4 & 1 & 4 & 1 \\
\hline LVEF (\%) & 39 & 41 & 12 & 41 & 12 & 37 & 10 \\
\hline
\end{tabular}

Continuous variables are presented as mean (SD) or median (IOR) and categorical variables as numbers $(\mathrm{n})$ and percent (\%).

ACEl, angiotensin-converting enzyme inhibitor; ARB, angiotensin receptor blocker; COPD, chronic obstructive pulmonary disease; CV, cardiovascular; HAART, highly active anti-retro viral therapy; HF, heart failure; NYHA, New York Heart Association. 
Table 2 Cox regression univariate and multivariate analysis for predictors of all-cause mortality

\begin{tabular}{|c|c|c|c|c|c|}
\hline \multirow[b]{2}{*}{ Variable } & \multicolumn{2}{|c|}{ Univariate } & \multicolumn{2}{|c|}{ Multivariate } & \multirow[b]{2}{*}{$p$ Value } \\
\hline & HR & $95 \% \mathrm{Cl}$ & HR & $95 \% \mathrm{Cl}$ & \\
\hline Age (years) & 1.03 & (1.02 to $\left.1.05^{*}\right)$ & 0.99 & (0.97 to 1.00$)$ & 0.159 \\
\hline Male gender & 1.17 & (0.72 to 1.90$)$ & 1.44 & (0.84 to 2.47 ) & 0.189 \\
\hline Residing in Dar es Salaam & 1.23 & (0.76 to 2.01 ) & & & \\
\hline No formal education & 1.91 & $\left(1.13\right.$ to $\left.3.22^{*}\right)$ & 2.34 & (1.29 to 4.24$)$ & 0.005 \\
\hline Unemployed & 1.38 & (0.85 to 2.25 ) & & & \\
\hline Inpatient & 9.04 & (5.23 to $15.62^{*}$ ) & 3.23 & (1.54 to 6.75$)$ & 0.002 \\
\hline \multicolumn{6}{|l|}{ Duration of heart failure } \\
\hline$\geq 6$ months & 1.17 & (0.17 to 1.99 ) & & & \\
\hline NYHA class & & & & & 0.535 \\
\hline II & & 1 & & 1 & \\
\hline III & 2.26 & (0.87 to 5.90$)$ & 0.92 & (0.32 to 2.64 ) & \\
\hline IV & 5.2 & (2.04 to $13.30^{*}$ ) & 0.66 & (0.21 to 2.08 ) & \\
\hline Diabetes & 1.81 & (0.97 to $\left.3.38^{*}\right)$ & 1.02 & (0.50 to 2.11 ) & 0.949 \\
\hline Atrial fibrillation & 10.9 & (6.56 to $18.00^{*}$ ) & 3.37 & (1.62 to 7.02$)$ & 0.001 \\
\hline Previous CV admission & 2.38 & $\left(1.40\right.$ to $\left.4.06^{*}\right)$ & 0.61 & (0.31 to 1.20$)$ & 0.154 \\
\hline Stroke & 1.12 & (0.35 to 3.57 ) & & & \\
\hline Asthma/COPD & 1.55 & (0.48 to 4.90$)$ & & & \\
\hline Tuberculosis & 1.07 & (0.26 to 4.38 ) & & & \\
\hline HIV & 1.69 & (0.41 to 6.92 ) & & & \\
\hline \multicolumn{6}{|l|}{ Heart failure cause } \\
\hline Ischaemic heart failure & 1.30 & (0.60 to 3.25 ) & & & \\
\hline Hypertensive heart failure & 0.79 & (0.45 to 1.14 ) & & & \\
\hline Rheumatic heart disease & 1.47 & (0.72 to 2.99 ) & & & \\
\hline Other heart failure causes ${ }^{\lambda}$ & & 1 & & & \\
\hline Pulmonary hypertension & 7.09 & (4.32 to $11.60^{*}$ ) & 2.11 & (1.06 to 4.19$)$ & 0.033 \\
\hline ACEI/ARB & 1.26 & (0.51 to 3.14 ) & & & \\
\hline$\beta$-Blockers & 1.00 & (0.62 to 1.64 ) & & & \\
\hline Body mass index $\left(\mathrm{kg} / \mathrm{m}^{2}\right.$ & & & & & 0.663 \\
\hline$<18.5$ & 2.16 & (0.85 to 5.48 ) & 1.56 & (0.53 to 4.64$)$ & \\
\hline $18.5-24.9$ & & 1 & & 1 & \\
\hline$\geq 25$ & 0.45 & $\left(0.26\right.$ to $\left.0.77^{*}\right)$ & 0.93 & (0.50 to 1.73 ) & \\
\hline Mean arterial BP (mm Hg) & 0.99 & $(0.98$ to $1.00 *)$ & 0.99 & (0.97 to 1.00$)$ & 0.087 \\
\hline Anaemia & 7.11 & (4.29 to $11.79^{*}$ ) & 2.27 & (1.16 to 4.45 ) & 0.017 \\
\hline Creatinine clearance (mL/min) & 0.99 & $(0.98$ to $1.00 *)$ & 0.98 & (0.97 to 1.00$)$ & 0.004 \\
\hline Total serum cholesterol (mmol/L) & 0.93 & (0.77 to 1.14 ) & & & \\
\hline \multicolumn{6}{|l|}{ Serum $\mathrm{Na}(\mathrm{mmol} / \mathrm{L})$} \\
\hline$<135$ & 1.59 & (0.22 to 1.39 ) & & & \\
\hline $135-145$ & 1 & & & & \\
\hline$>145$ & 0.87 & (0.45 to 1.69 ) & & & \\
\hline Serum K+ (mmol/L) & 1.21 & (0.85 to 1.72 ) & & & \\
\hline$<3.5$ & 0.56 & (0.22 to 1.39$)$ & & & \\
\hline $3.5-5.0$ & 1 & & & & \\
\hline$>5.0$ & 1.43 & (0.68 to 3.01 ) & & & \\
\hline LVEF, $<45 \%$ & 2.98 & (1.52 to $\left.5.84^{*}\right)$ & 1.57 & (0.75 to 3.25 ) & 0.230 \\
\hline
\end{tabular}

${ }^{*}=$ Variables with $p<0.10$ in univariate Cox regression analysis.

$\lambda=$ Cardiomyopathies (eg, dilated, hypertrophic, restrictive and postpartum) were merged to form a category of other heart failure causes, for the purpose of Cox regression analysis. ACEl, angiotensin-converting enzyme inhibitor; ARB, angiotensin receptor blocker; COPD, chronic obstructive pulmonary disease; CV, cardiovascular; NYHA, New York Heart Association.

respectively (figure $3 \mathrm{~B}, \mathrm{C}$ ). Patients with a formal education had a 6-month survival of $92 \%$ vs $80 \%$ among those without $(\mathrm{p}<0.014$; figure $3 \mathrm{D})$.

Univariate and multivariate predictors of mortality are displayed in table 2. The multivariate predictors of mortality (table 2 and figure 4) were atrial fibrillation, HR 3.4 (95\% CI 1.6 to 7.0$)$; in-patient status 3.2 (1.5 to 6.8$)$; anaemia $2.3(1.2$ to 4.5 ); pulmonary hypertension 2.1 (1.1 to 4.2 ); creatinine clearance 0.98 ( 0.97 to 1.00$)$ and lack of formal education 2.3 (1.3 to 4.2$)$.

\section{DISCUSSION}

The TaHeF study provides clinically important information on aetiological and prognostic factors in a population of $\mathrm{HF}$ patients in whom such data still are limited. Hypertension is emerging as a predominant cause of HF and anaemia, atrial fibrillation and lack of education were independent predictors of mortality. These conditions are all possible to detect and manage. Accordingly, it opens for targeted public health interventions with the intention to impact on the incidence and prognosis of HF in Tanzania. 


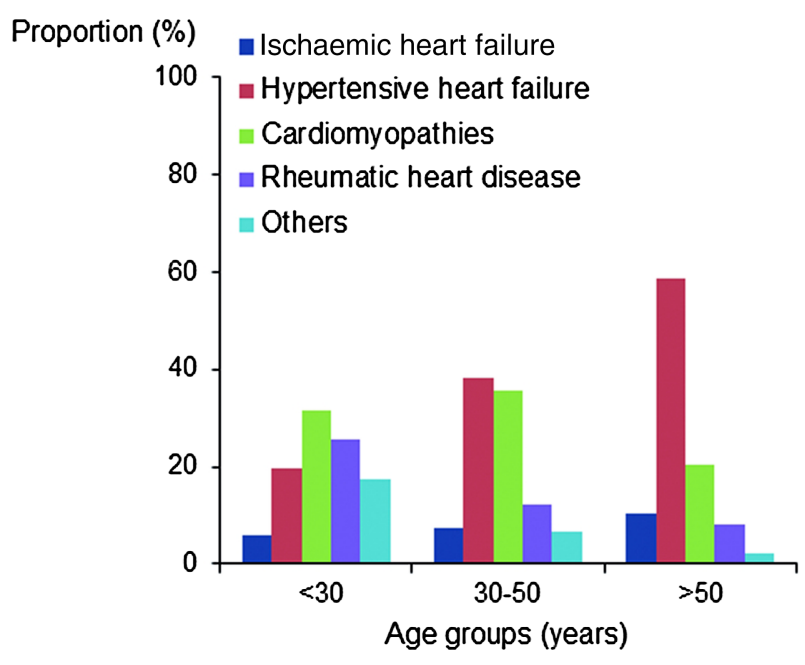

Figure 2 Causes of heart failure in percentages within age groups. Dark blue=ischemic heart disease; red=hypertensive heart disease; green=cardiomyopathies; lilac=rheumatic heart disease; light blue $=$ other reasons.

Rheumatic heart disease was a less common than expected cause of HF, and the role of ischaemic heart disease remains fairly low. The relatively low prevalence of ischaemic aetiology contrasts the situation in developed countries while the increasing role of hypertension is similar. Thus, the TaHeF study discloses a change in the aetiological pattern of HF in SSA, where rheumatic heart disease and cardiomyopathy have previously

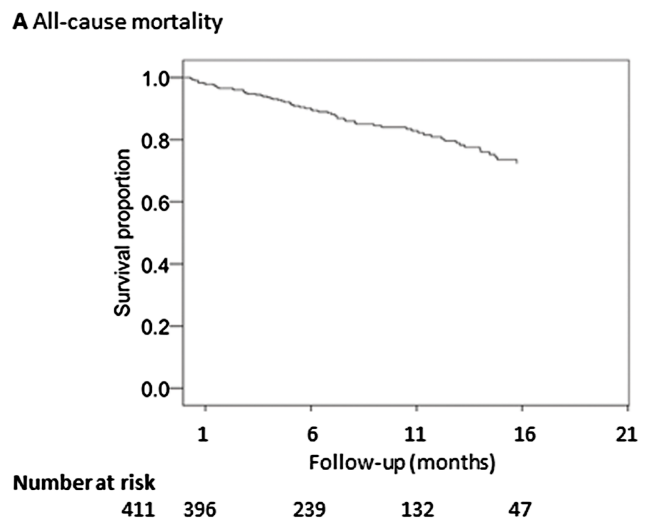

C All-cause mortality by presence of atrial fibrillation

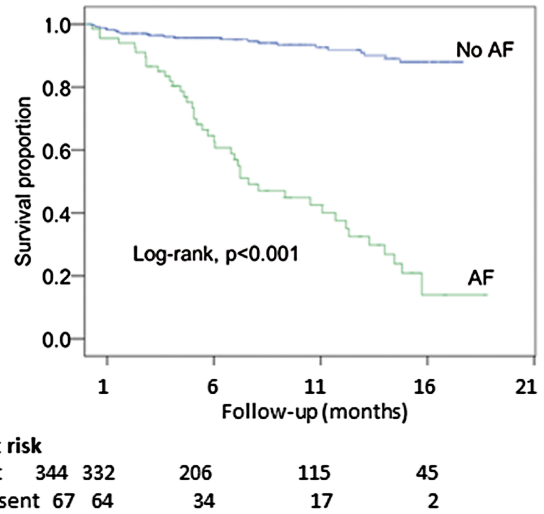

been dominant. The etiological role of hypertension in the present study confirms the THESUS-HF and Heart of Soweto Studies, ${ }^{10}$ of HF in SSA. A mean age of 55 is also congruent with previous studies reporting a mean age of 52 in $\mathrm{SSA}^{3} 78$ compared with over 70 years in developed countries. ${ }^{5} 12$

The present finding of a predominant role of hypertension in a relatively young HF population has important public health implications. It may reflect a late detection of and/or poorly treated hypertension and should encourage improved screening, enabling early detection followed by target driven treatment according to available guidelines. ${ }^{13}$ Previous studies in SSA show that less than $20 \%$ of the hypertensive patients are within therapeutic limits. ${ }^{14} 15$ Despite the predominance of hypertension, only $9 \%$ had creatinine clearance $<30 \mathrm{~mL} / \mathrm{min}$, closely comparable to THESUS-HF in which a glomerular filtration rate $<30 \mathrm{~mL} / \mathrm{min} / 1.73 \mathrm{~m}^{2}$ was present in $8 \%$. $^{7}$ This is less than the frequently reported $16-20 \%$ in developed countries, ${ }^{16} 17$ indicating that target organ damage may vary geographically, ethnically and in relation to comorbidities. The more frequent renal failure in HF seen in developed countries may represent long-standing HF and the cardiorenal syndrome as opposed to direct hypertensive damage. The present data do not permit further elaboration on this issue.

Another finding of interest was the high prevalence of anaemia despite a low cut-off value of haemoglobin $(<10 \mathrm{~g} / \mathrm{dL})$, imposing a higher risk for mortality. This finding needs further elaboration, including an exploration of the underlying causes and the pathophysiological relation to HF.

Additional factors predicting mortality in $\mathrm{HF}$ in the present population were not dissimilar from those known from developed countries, atrial fibrillation, ${ }^{9}{ }^{18} 19$ pulmonary

B All-cause mortality by haemoglobin level

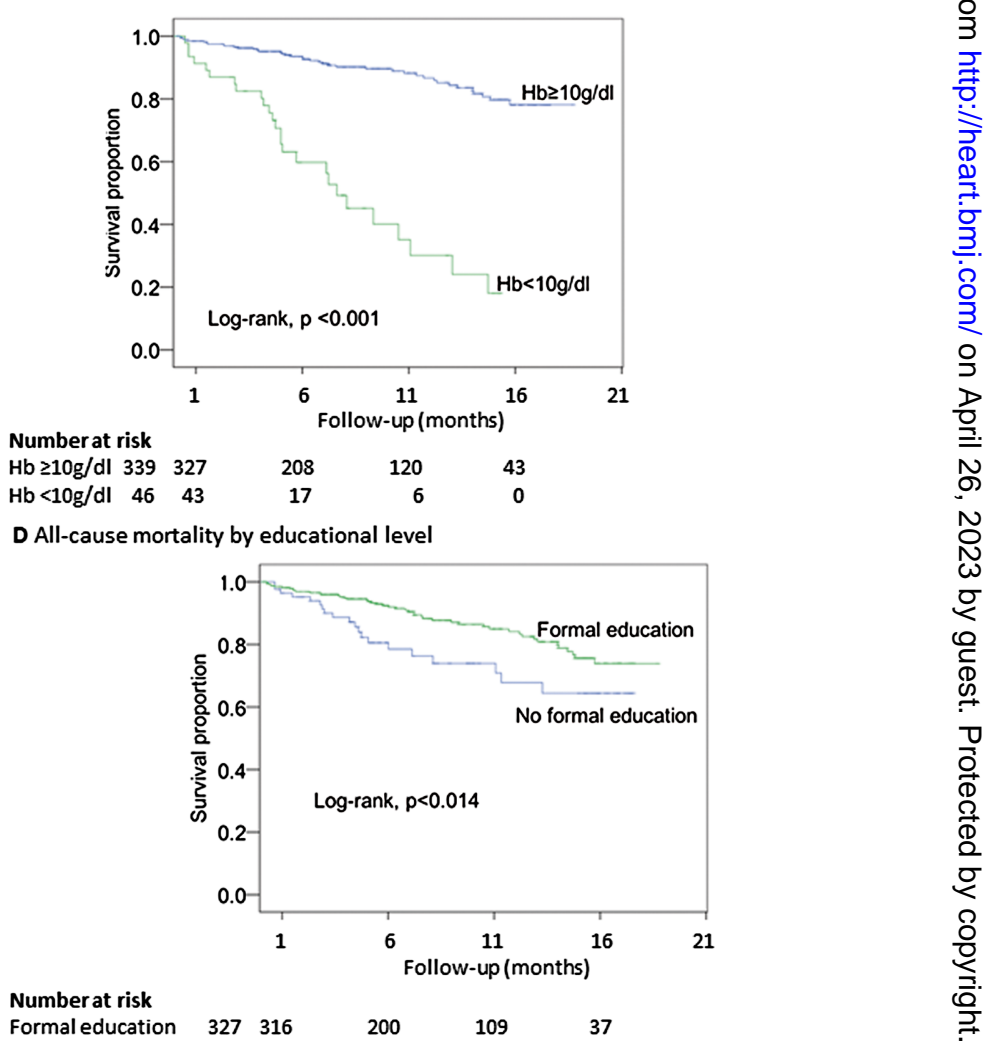

$\begin{array}{lrrrrr}\text { Formal education } & 327 & 316 & 200 & 109 & 37 \\ \text { No formal education } & 84 & 79 & 40 & 23 & 10\end{array}$

Figure 3 (A-D). Kaplan-Meier survival curves by different subgroups. (A) In the total cohort; (B) by the presence of anaemia; (C) by the presence of atrial fibrillation $(A F) ;(D)$ in relation to educational level. 


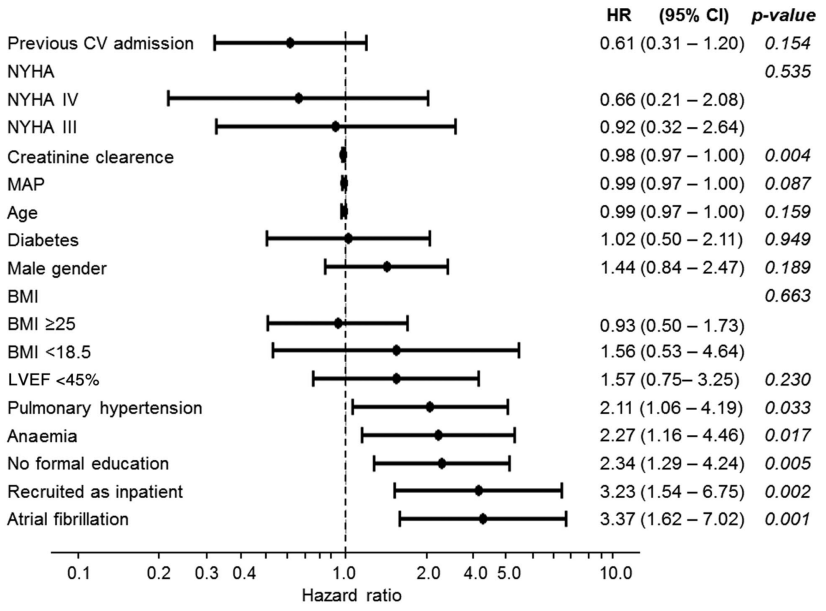

Figure 4 Multivariate HRs for all-cause mortality. BMI, body mass index; $\mathrm{CV}$, cardiovascular; MAP, mean arterial pressure; NYHA, New York Heart Association functional classification.

hypertension, ${ }^{20} 21$ renal dysfunction ${ }^{22}$ and the educational level. ${ }^{23} 24$ This implies that several risk factors for mortality may be similar regardless of the underlying cause of HF. Of particular concern is atrial fibrillation, which was present in $16 \%$ and associated with a HR of 3.4. Yet warfarin was used in less than $3 \%$ of all patients opening for a considerable therapeutic improvement. In THESUS-HF, ${ }^{25}$ pulmonary disease and low systolic blood pressure were associated with mortality. Although these factors were associated with increased or decreased numerical risk in the present cohort, this risk did not reach statistical significance. The present data give support to previous reports from SSA, ${ }^{25}$ on the lack of an association between age, gender, ACEI/ARBs and low sodium and mortality, which contrasts with developed countries. ${ }^{5} 26$ A potential explanation is that such factors have a more limited role in the pathogenesis of HF progression in populations in which ischaemic heart disease is a less common underlying cause. Another reason may be that a majority of the present patients were in a relatively stable condition and of younger age and that a third had preserved LVEF. These differences from developed countries deserve further analyses and may influence interventional strategies.

From a therapeutic perspective, the use of ACEI/ARBs was as high and in accordance with guidelines. ${ }^{27}$ This supports THESUS-HF, ${ }^{7}$ in which $87 \%$ of the admitted patients were on a ACEI/ARBs 1 month after discharge. In contrast, the use of $\beta$-blockers was low, confirming previous reports from SSA. ${ }^{7} 9$ The reasons are unknown but may relate to the relatively low prevalence of ischaemic heart disease or a remaining fear that $\beta$-blockade may worsen HF. Although $\beta$-blockers were less effective in preventing death in African-American patients with HF as compared with white patients, ${ }^{28}$ efforts should be made at improving adherence to guideline-based HF therapy.

The strength of the present report is that it is based on a fairly large and well-characterised study population with minor loss to follow-up, in a resource-limited country in which HF is mainly non-ischaemic. This expands the understanding of HF beyond what has been reported from developed countries and other SSA settings. While some predictors of mortality have been described in both developed countries and SSA, the large risks associated with reduced LVEF, anaemia and pulmonary hypertension are of interest.

There are limitations to this study. Some patients were lost to follow-up even if they were fewer than expected given the study setting. The relatively low number of events affected the statistical power, but it was still sufficient to identify at least some clinically important factors that may be intervened against. The absence of natriuretic peptides and invasive ischaemic HF diagnosis/verification may also be seen as limitations. Finally, the study was conducted in an urban referral hospital. Thus, the findings may not be representative for HF seen in rural SSA settings.

\section{CONCLUSIONS}

Hypertension emerges as an important cause of HF in Tanzania similar to other SSA countries, whereas rheumatic heart disease is becoming less important. Given the young age of the HF patients, hypertension must be seen as a prioritised target for early detection and intervention. Anaemia is common among HF patients and is associated with increased mortality, a finding that should be further explored. Atrial fibrillation is less common than in developed countries, but if present, then strongly associated with increased mortality. Yet warfarin is used to a remarkably low extent. Facilitation of its use may favourably impact the prognosis. Lack of formal education is associated with increased HF mortality, suggesting a need for increased accessibility to education and improved public disease awareness.

\section{Key messages}

What is already known on this subject?

- The aetiology, clinical characteristics, therapy and prognosis of heart failure (HF) have been extensively studied in developed countries but remain largely unexplored in Sub-Saharan Africa (SSA).

- HF aetiologies in SSA are changing towards a pattern known from the developed world, with less dominance of rheumatic heart disease and cardiomyopathies.

- Mortality and its predictors have been carefully studied in the developed world but not in SSA.

What this study adds

- Hypertension is an increasingly common aetiology of HF while rheumatic heart disease is less important and coronary heart disease remains uncommon.

- Anaemia and atrial fibrillation and lack of formal education are independent predictors of mortality in HF in Tanzania.

- Warfarin use is exceedingly low in Tanzania even in a setting of $\mathrm{HF}$ and atrial fibrillation.

- The therapeutic use of angiotensin-converting enzyme inhibitors/ angiotensin receptor blockers is high while that of $\beta$-blockers is low.

How might this impact on clinical practice?

- Hypertension is a potential target for intervention to reduce the incidence of HF in Africa, and atrial fibrillation, anaemia and education are potential targets of intervention to reduce mortality in HF.

Acknowledgements We thank MUHAS, Karolinska Institute and Muhimbili National Hospital's staff for collaboration in implementing this study. We would also like to thank all patients who contributed to these findings.

Contributors All authors contributed significantly to the manuscript and meet the criteria for authorship as follows. AM: study concept and design; acquisition of data; statistical analysis; analysis and interpretation of data; drafting of manuscript and 
funding. CH: study design; statistical analysis; analysis and interpretation of data; critical revision of manuscript and supervision. JL: study concept and design; acquisition of data; analysis and interpretation of data; critical revision of manuscript; administrative support; supervision and funding. PK: acquisition of data; analysis, interpretation of data and revision of manuscript. JM and LR: study concept and design; analysis and interpretation of data; critical revision of manuscript; supervision; administrative support and funding. LHL: study concept and design; statistical analysis; analysis and interpretation of data; critical revision of manuscript; administrative support; supervision and funding. AM, CL and LHL had full access to all data and take full responsibility for the accuracy of data analysis.

Funding The authors disclosed the receipt of the following financial support for the research, authorship and/or publication of this article: Unit of Cardiology, Department of Medicine, Karolinska Institute; The Swedish Heart and Lung Foundation; Stockholm County Council; The Government of Tanzania through the Ministry of Health funds Medical services in Tanzania. AM was supported by the Swedish International Development Cooperation Agency (SIDA) through a joint capacity strengthening programme with MUHAS and by the Germany exchange programme for education (DAAD).

\section{Competing interests None.}

Ethics approval The TaHeF study was approved by the ethical review board of the Muhimbili University of Health and Allied Sciences (MUHAS). All patients provided written informed consent.

Provenance and peer review Not commissioned; externally peer reviewed.

Transparency declaration AM affirms that the manuscript is honest, accurate and a transparent account of the study being reported.

Data sharing statement Patient-level data, full dataset and statistical codes are available from the corresponding author. Informed consent for data sharing was not obtained, but the presented data are anonymised and risk of identification is low.

\section{REFERENCES}

1 Go AS, Mozaffarian D, Roger VL, et al. Executive summary: heart disease and stroke statistics-2013 update: a report from the American Heart Association. Circulation 2013;127:143-52.

2 Kengne AP, Ntyintyane LM, Mayosi BM. A systematic overview of prospective cohort studies of cardiovascular disease in sub-Saharan Africa. Cardiovasc J Afr 2012;23:103-12.

3 Mayosi BM. Contemporary trends in the epidemiology and management of cardiomyopathy and pericarditis in sub-Saharan Africa. Heart 2007:93:1176-83.

4 Ntusi NBA, Mayosi BM. Epidemiology of heart failure in sub-Saharan Africa. Expert Rev Cardiovasc Ther 2009;7:169-80.

5 Cleland JGF, Swedberg K, Follath F, et al. The EuroHeart Failure survey programme -a survey on the quality of care among patients with heart failure in Europe Part 1: patient characteristics and diagnosis. Eur Heart J 2003;24:442-63.

6 Rouleau J, Shenasa M, de Champlain J, et al. Predictors of survival and sudden death in patients with stable severe congestive heart failure due to ischemic and nonischemic causes: a prospective long term study of 200 patients. Can I Cardiol 1990;6:453-60.

7 Damasceno A, Mayosi BM, Sani M, et al. The causes, treatment, and outcome of acute heart failure in 1006 Africans from 9 countries. Arch Intern Med 2012;172:1386-94.

8 Sliwa K, Mayosi BM. Recent advances in the epidemiology, pathogenesis and prognosis of acute heart failure and cardiomyopathy in Africa. Heart 2013;99:1317-22.

9 Familoni OB, Olunuga TO, Olufemi BW. A clinical study of pattern and factors affecting outcome in Nigerian patients with advanced heart failure. Cardiovasc J Afr 2007; 18:308-11.
10 Stewart S, Wilkinson D, Hansen C, et al. Predominance of heart failure in the Heart of Soweto Study Cohort: emerging challenges for Urban African Communities. Circulation 2008:118:2360-7.

11 McKee PA, Castelli WP, McNamara PM, et al. The natural history of congestive heart failure: the Framingham study. N Engl J Med 1971;285:1441-6.

12 Sliwa K, Hilfiker-Kleiner D, Petrie MC, et al. Current state of knowledge on aetiology, diagnosis, management, and therapy of peripartum cardiomyopathy: a position statement from the Heart Failure Association of the European Society of Cardiology Working Group on peripartum cardiomyopathy. Eur I Heart Fail 2010;12:767-78

13 Mancia G, Fagard R, Narkiewicz K, et al., Authors/Task Force Members. 2013 ESH/ESC Guidelines for the management of arterial hypertension: The Task Force for the management of arterial hypertension of the European Society of Hypertension (ESH) and of the European Society of Cardiology (ESC). Eur Heart J 2013;34:2159-219.

14 Addo J, Smeeth L, Leon DA. Hypertension in sub-saharan Africa: a systematic review. Hypertension 2007;50:1012-8.

15 Kayima J, Wanyenze RK, Katamba A, et al. Hypertension awareness, treatment and control in Africa: a systematic review. BMC Cardiovasc Disord 2013;13:54.

16 Nieminen MS, Brutsaert D, Dickstein K, et al. EuroHeart Failure Survey II (EHFS II): a survey on hospitalized acute heart failure patients: description of population. Eur Heart J 2006;27:2725-36.

17 Adams KF Jr, Fonarow GC, Emerman CL, et al. Characteristics and outcomes of patients hospitalized for heart failure in the United States: rationale, design, and preliminary observations from the first 100,000 cases in the Acute Decompensated Heart Failure National Registry (ADHERE). Am Heart J 2005;149:209-16.

18 Marte T, Saely CH, Schmid F, et al. Effectiveness of atrial fibrillation as an independent predictor of death and coronary events in patients having coronary angiography. Am J Cardiol 2009;103:36-40.

19 McManus DD, Saczynski JS, Lessard D, et al. Recent trends in the incidence, treatment, and prognosis of patients with heart failure and atrial fibrillation (the Worcester Heart Failure Study). Am J Cardiol 2013;111:1460-5.

20 Szwejkowski BR, Elder DHJ, Shearer F, et al. Pulmonary hypertension predicts all-cause mortality in patients with heart failure: a retrospective cohort study. Eur J Heart Fail 2012;14:162-7.

21 Bursi F, McNallan SM, Redfield MM, et al. Pulmonary pressures and death in heart failure: a community study. J Am Coll Cardiol 2012;59:222-31.

22 Smith GL, Lichtman JH, Bracken MB, et al. Renal impairment and outcomes in heart failure: systematic review and meta-analysis. I Am Coll Cardiol 2006:47:1987-96.

23 Peterson PN, Shetterly SM, Clarke CL, et al. Health literacy and outcomes among patients with heart failure. JAMA 2011;305:1695-701.

24 Oyoo GO, Ogola EN. Clinical and socio demographic aspects of congestive heart failure patients at Kenyatta National Hospital, Nairobi. East Afr Med J 1999;761:23-7.

25 Sliwa K, Davison BA, Mayosi BM, et al. Readmission and death after an acute heart failure event: predictors and outcomes in sub-Saharan Africa: results from the THESUS-HF registry. Eur Heart J 2013. http://eurheartj.oxfordjournals.org/cgi/doi/10. 1093/eurheartj/eht393 (accessed 11 Oct 2013)

26 Pocock SJ. Predictors of mortality and morbidity in patients with chronic heart failure. Eur Heart I 2005;27:65-75.

27 McMurray JJV, Adamopoulos S, Anker SD, et al. Authors/Task Force Members. ESC Guidelines for the diagnosis and treatment of acute and chronic heart failure 2012: The Task Force for the Diagnosis and Treatment of Acute and Chronic Heart Failure 2012 of the European Society of Cardiology. Developed in collaboration with the Heart Failure Association (HFA) of the ESC. Eur J Heart Fail 2012;14:803-69.

28 Lanfear DE, Hrobowski T, Peterson EL, et al. Association of beta blocker exposure with outcomes in heart failure differs between African American and white patients. Circ Heart Fail 2012;5:202-8. Circheartfailure.111.965780. 